\title{
REVISTA
}

\section{A AVALIAÇÃo DA AUTORIA NO ENEM: DIÁlOGOS A PARTIR DE MIKHAIL BAKHTIN E MICHEL FOUCAULT}

\section{AUTHORSHIP EVALUATION IN ENEM: DIALOGUES FROM MIKHAIL BAKHTIN AND MICHEL FOUCAULT}

\author{
Guilherme Brambila ${ }^{1}$ \\ Luciano Novaes Vidon ${ }^{2 *}$ \\ ${ }^{1}$ Universidade Federal do Espírito Santo. E-mail: guilhermebrambilamanso@ hotmail.com \\ ${ }^{2}$ Universidade Federal do Espírito Santo. E-mail: profvidon@gmail.com \\ *Autor para correspondência
}

Artigo submetido em 14/10/2019, aceito em 05/11/2019 e publicado em 17/12/2019

\begin{abstract}
Resumo: Este trabalho tem o objetivo de suscitar reflexões a respeito da autoria na conjuntura da prova de redação do Exame Nacional do Ensino Médio (Enem). Pretende-se, especificamente, analisar como a autoria é vista e requerida em uma cartilha de redação oficial do exame, publicada no ano de 2016. O norteamento teórico-filosófico que guia este estudo está embasado nos conceitos de autor em Mikhail Bakhtin (2011), em interface ao de autor em Michel Foucault (2006). O trabalho guia-se metodologicamente por uma perspectiva indiciária (GINZBURG, 1986) fundamentada em uma base dialógica de observação. Os resultados da análise apontam que a visão institucional sobre a autoria no Enem afasta tal processo do campo da subjetividade dialógica e o aproxima de uma racionalização monológica pela via da escrita.
\end{abstract}

Palavras-chave: Enem; autoria; avaliação.

\begin{abstract}
This paper aims at promoting discussions about authorship at the juncture of the High School National Exam (Enem) essay test. Specifically, we intend to analyze how authorship is viewed and required in an official writing exam booklet, published in 2016. The theoretical-philosophical perspective that guides this study is based on the author's concepts in Bakhtin (2011), in interface to the author concept in Foucault (2006). The work is methodologically guided by an indiciary perspective (GINZBURG, 1986) based on a dialogic basis of observation. The results of the analysis indicate that the institutional view on authorship in Enem takes this process away from the dialogical field of subjectivity and brings it closer to a monological rationalization through writing.
\end{abstract}

Keywords: Enem; authorship; evaluation.

\section{INTRODUÇÃO}

O diálogo, no sentido bakhtiniano do termo, propicia aos sujeitos oportunidades de se constituírem autores. Em meio à interação verbal, por exemplo, colocamos em tensão nossa existência no mundo e em relação aos outros com os quais dialogamos 
na e pela linguagem. Assim, é possível que já estabeleçamos que a autoria, nesse prisma dialógico de observação, é um processo que reflete-refrata a singularidade de cada sujeito em suas enunciações.

Em posse dessa perspectiva acerca da autoria, somos convidados a pensá-la em sociedade como uma construção singular de cada sujeito e que se justifica pelas intenções discursivas e interativas que cada um pretende estabelecer com o outro, em esferas de interação e por meio de gêneros discursivos diversos.

Todavia, assim como todo elemento próprio da dialogicidade humana, a autoria pode passar por idealizações que, consequentemente, a enclausuram em um modus operandi específico, exigindo sujeitos autores que atendam a essa modelização (BRAMBILA, 2018). Como exemplo, e que é alvo da problematização deste artigo, a autoria como item a ser avaliado no sistema de competências da redação do Exame Nacional do Ensino Médio $(\text { Enem })^{1}$ é um caso em que perceberemos uma idealização que atinge uma considerável parte da população brasileira todos os anos.

A prova de redação, item constituinte do Enem e que repetidamente é exigida no gênero texto dissertativoargumentativo, requer a produção de um texto em que o candidato disserte sobre um tema de cunho social fornecido pelo exame. Há textos motivadores para auxiliar no entendimento do tema e uma das exigências para o texto é que haja uma proposta de intervenção à problemática contida no assunto. $\mathrm{O}$ texto produzido pelo candidato passa por uma banca avaliadora que, com base em uma tabela de competências, atribui uma nota que poderá variar de 0 a 1000.

1 O Enem é uma avaliação do Ministério da Educação, iniciada em 1998, com o objetivo de avaliar a qualidade do ensino médio no país. Além disso, seu resultado também é utilizado para ranqueamento e acesso ao ensino superior em universidades públicas brasileiras, por meio do Sistema de Seleção Unificada (Sisu), assim como em algumas universidades no exterior.
Diante

dessa rápida contextualização, o presente artigo tem como proposta principal um estudo crítico do discurso institucional do sistema de avaliação do Enem a respeito da autoria. Em outras palavras, trabalharemos focados no objetivo de investigar dialogicamente quais perspectivas o Estado brasileiro, responsável pela produção e aplicação do Enem, tem em relação à autoria, a fim de compreender possíveis motivações que o leva a pautar a autoria como passível de avaliação e atribuição de valor.

Como base teórica desta investigação, buscaremos dialogar com as perspectivas de autoria em Mikhail Bakhtin (2011), em interface com a perspectiva de Michel Foucault (2006), na intenção de construir uma rede dialógica de compreensão deste processo e que possa orientar as problematizações destinadas ao corpus.

Por meio de uma perspectiva de observação indiciária (GINZBURG, 1986), analisaremos trechos que dizem respeito à autoria no e-book Redação do Enem 2016: cartilha do participante, manual fornecido gratuitamente pelo Instituto Nacional de Estudos e Pesquisas Anísio Teixeira (Inep).

Este trabalho, traz à tona resultados obtidos em uma pesquisa de mestrado (2017), e justifica sua existência por suscitar questionamentos atuais que dizem respeito ao sistema de avaliação textual do Estado brasileiro e, consequentemente, se reflete no ensino-aprendizagem de produção de textos da esfera escolar.

\section{A INTERFACE DIALÓGICA DA AUTORIA EM BAKHTIN}

Falar de autoria, em Bakhtin, pode nos colocar dentro de uma gama de discussões. É possível que nos reportemos às polêmicas envolvendo a autoria de algumas obras produzidas pelo chamado Círculo de Bakhtin - como é o caso, por exemplo, de Marxismo e Filosofia da Linguagem ([1929] 2017), que 
historicamente foi cercado de extensas discussões sobre a autoria de Bakhtin ou Volóchinov na obra -, ou também sobre autoria enquanto conceito, oriundo da interface com a literatura - por conta, principalmente, de discussões em Problemas da Poética de Dostoiévski (2005) e no ensaio "O autor e a personagem", publicado em Estética da criação verbal (2011 [1979]). Sobre essa questão, Faraco (2005, p.37) evidencia que

O tema do autor e da autoria está presente, em maior ou menor grau, em quase todos os escritos conhecidos de Bakhtin. Trata-se de um tema que envolve uma extensa elaboração de natureza filosófica (já que, desde cedo, Bakhtin esteve empenhado em construir uma estética geral) e que conheceu diferentes desdobramentos a cada novo retorno a ele.

Fizemos essa rápida retomada como uma forma de salientar que, apesar das já constantes contribuições e leituras sobre essa questão, haverá sempre algo ainda a ser dialogado.

Partindo da constante demanda em torno do assunto e tendo como intenção também trabalhar a possibilidade de se pensar a subjetividade e a autoria na contemporaneidade, traremos, nas próximas linhas, perspectivas bakhtinianas que tangem o sujeito e o processo de autoria, buscando constatar a rede de alcances e possibilidades do conceito para os estudos da linguagem.

Como dito anteriormente, no texto "O autor e a personagem", Bakhtin dedica grande reflexão à questão do autor. Bakhtin (2011, p. 4) defende a impossibilidade de que o autor, principalmente o da obra literária, tenha controle absoluto sobre sua personagem no plano estético:

O autor não encontra de imediato para a personagem uma visão não aleatória, sua resposta não se torna imediatamente produtiva e de princípio, e do tratamento axiológico único desenvolve-se o todo da personagem: esta exibirá muitos trejeitos, máscaras aleatórias, gestos falsos e atos inesperados em função das respostas volitivo-emocionais e dos caprichos de alma do autor [...].

Tal questão nos instiga a pensar que, apesar de certa soberania do autor em seu ato criativo sobre a personagem, esta, como fruto de um processo dialógico, poderá comportar uma não exatidão no plano estético, transbordando para o ético.

Percebemos, então, que a autoria, em Bakhtin, está intimamente ligada à subjetividade, sendo esta sua precedente. É pela subjetividade que se realiza a polifonia de discursos alimentados pela interação histórica e social. É por essa via que o autor se constitui em relação ao outro e a si mesmo, tendo, portanto, a capacidade de criar e dialogar com a criação e a impossibilidade de tê-la criado "sozinho".

Vale, também, ressaltar que os postulados de Bakhtin (e do Círculo) sobre a subjetividade pautam-se no materialismo histórico-dialético. Em outras palavras, entende-se o sujeito como aquele que vivencia social e historicamente valores e contextos discursivos de maneira real, sendo sua atividade ética e estética um reflexo dessa vivência. Tal perspectiva se afasta, portanto, de noções abstratas, idealistas e psicologicistas $^{2}$ de sujeito, já que ele, na visão bakhtiniana, é constituído por suas práticas e interações por meio de circunstâncias reais de enunciação.

Essa não abstração/idealização da subjetividade e do processo de autoria, defendida por Bakhtin, também nos leva à atenção acerca do acabamento do enunciado, que também é real e concreto. Haverá, nesse plano, um conjunto de construções relativamente estáveis que dão acabamento, mesmo que não completamente, ao enunciado, proporcionando ao leitor o todo estético do texto e da personagem. Esse todo estético, portanto, torna-se uma arena de interação na qual os sujeitos tomam suas vozes de

2 É possível incluir aqui certa visão romântica da psicanálise freudiana, como discutido por Bakhtin/Volochínov em $O$ freudismo: um esboço crítico ([1927] 2012). 
autores e enchem o enunciado de possibilidades discursivas dialogicamente.

É nesse raciocínio que conseguimos pontuar a interface do dialogismo com a questão da autoria. O diálogo é algo constitutivo da interação dos sujeitos que são motivados, constantemente, a enunciar e a responder às vozes dos outros que os atravessam nessa(s) interação(ões). O processo de autoria, então, surge da ação do sujeito que se põe a responder às vozes que o atravessam constitutivamente, por meio da proposição de um eu estético - o autorcriador, na arquitetônica bakhtiniana -, atravessado por um eu ético - o autorpessoa, no plano do 'vivido' -, que se incumbe da responsabilidade de fazer essas vozes acontecerem no todo do enunciado.

Entretanto, tal processo não encontra sua finidade na completude do enunciado, já que os mesmos são de natureza dialógica e continuam seu movimento quando entram em contato com a discursividade do outro que os recepciona, nunca passivamente. Este outro, como já afirmado por Clark e Houlquist (2004), é um destinatário ativo, um ser que não se limita à compreensão passiva diante do locutor. Dessa forma, nem a obra tampouco a autoria, dentro da perspectiva bakhtiniana, são estanques. Haverá sempre alguém que terá certa autoria autorizada a recepcionar essa obra e transformá-la por meio de sua enunciação, tendo algo a mais a dizer sobre ela.

A partir dessas considerações, o autor em Bakhtin pode ser compreendido para os estudos da linguagem como aquele que não parte de uma gênese adâmica, mas que se constitui a partir de suas relações com outros sujeitos que o enriquecem, que o constituem axiologicamente pela via de um diálogo que é tenso, inconcluso e contínuo.

Ao posicionarmos essa autoria dentro do campo textual discursivo poderemos, consequentemente, entendê-la como a incapacidade de o sujeito se colocar como autoridade única de seu texto, mas que consegue fazer escolhas, que são próprias de sua subjetividade, constituídas de vivências materiais e concretas, para posicionar as vozes de seu discurso na tentativa de colocá-las em tensão de maneira única e singular.

Assim, o texto de um autor, na perspectiva bakhtiniana, enquanto enunciado concreto (BAKHTIN 2011 [1979]), não é enxergado como aquele em que há um eu que prevalece. Esse texto/enunciado é aquele em que o sujeito autor recupera e dialoga com vozes discursivas diversas e realiza esse processo de maneira única, irrepetível.

Por meio do entendimento do processo de autoria como algo próprio da enunciação do sujeito, que é única e irrepetível, é possível problematizar certas construções ilusórias que se fazem sobre a subjetividade e a produção textual, especificamente as que acontecem dentro de circunstâncias avaliativas, como a redação do Enem.

Ao percebermos a impossibilidade de conceber um autor desprovido de sua subjetividade dialógica, consideraremos problemática também a existência de parâmetros que avaliem a autoria, principalmente no campo textual-discursivo. Nesse prisma, notamos que a imposição de autoria e subjetividade específicas monológicas - em nada se aproxima de uma tentativa bem-intencionada de potencializar o processo enunciativo-textual subjetivo, mas, sim, atua de modo a dessubjetivar (VIDON, 2013) aquele que escreve, para inseri-lo ou exclui-lo de grupos e esferas sociais.

Buscaremos, na próxima seção, trazer as considerações de autoria em Foucault (2006), estabelecendo um diálogo com a proposta bakhtiniana, a fim de construir uma base teórico-filosófica que nos guiará nas análises pretendidas.

\section{O AUTOR A PARTIR DE FOUCAULT}

Em Foucault (2006), o autor está relacionado à sua função na obra. Possenti 
(2001, p. 17) esclarece o que seria essa função-autor, ao afirmar que

[...] a função-autor é, em primeiro lugar, histórica, tanto no sentido de que não se caracteriza a partir de uma personalidade quanto no sentido de que ela se modifica em decorrência das alterações e diversificações das modalidades enunciativas.

A partir dessa primeira consideração, sigamos para alguns parâmetros, traçados por Foucault (2006, p. 264-265), que circundam o autor:

$\left.1^{\circ}\right)$ O nome do autor: impossibilidade de tratá-lo como uma discrição definida; mas impossibilidade igualmente de tratá-lo como um nome próprio comum.

$2^{\circ}$ ) A relação de apropriação: o autor não é exatamente nem o proprietário nem o responsável por seus textos; não é nem o produtor nem o inventor deles. Qual é a natureza do speech act que permite dizer que há obra?

$3^{\circ}$ ) A relação de atribuição: O autor é, sem dúvida, aquele a quem se pode atribuir o que foi dito ou escrito. Mas a atribuição - mesmo quando se trata de um autor conhecido - é o resultado de operações críticas complexas e raramente justificadas. As incertezas do opus.

$4^{\circ}$ ) A posição do autor: Posição do autor no livro (uso dos desencadeadores; funções dos prefácios; simulacros do copista, do narrador, do confidente, do memorialista). Posição do autor nos diferentes tipos de discurso (no discurso filosófico, por exemplo). Posição do autor em um campo discursivo (o que é o fundador de uma disciplina? O que pode significar o 'retorno a...' como momento decisivo na transformação de um campo discursivo?)

Analisemos o primeiro parâmetro que se atrela ao autor na perspectiva foucaultiana, a respeito do nome. Conforme Dorigatti (2004, p. 2), "o nome de autor assegura uma função classificativa, onde agrupa e delimita determinados textos, caracteriza um certo modo de ser discursivo". Podemos refletir sobre a função que o nome do autor possui como um ponto socialmente visível que reflete para a sociedade os discursos que esse autor traz em sua obra.

Assim, compreendemos a função que o nome tem para o autor como um elemento de caráter dúbio. $\mathrm{O}$ nome, que se apresenta antes mesmo do próprio sujeito que produz a obra, poderá ser significado para exaltar ou destruir o autor perante a sociedade. Isso se deve, claramente, ao fato de que o autor não garante a sua autoria em si mesmo, mas às formas de interação que a sociedade realizará com aquilo que estiver em seu nome.

É nessa elaboração que percebemos, nas palavras de Foucault, um caráter enfático ao afirmar que o nome do autor não se relaciona com o caráter stricto do termo, mas que funciona de maneira exclusivamente social. É na sociedade, em que as vozes institucionais estão incluídas, que o nome do autor será significado e valorado, conforme interagem com o que é produzido pelo mesmo.

$\mathrm{Na}$ sequência, e de maneira relacionada ao primeiro aspecto, Foucault estabelece uma relação de apropriação ao lidar com aquilo que o autor produz. Encontramos, nesse ponto, uma convergência com os pressupostos bakhtinianos sobre a polifonia. Isso se justifica porque, assim como Bakhtin, Foucault defende a impossibilidade de invenção de discursos, propondo pensarmos na autoria desse autor como parte de um movimento dialógico e subjetivo que só existe por intermédio da existência de outras vozes discursivas que permearão as escolhas e, consequentemente, a constituição autoral.

Entretanto, ao nos atentarmos à rede de significados que o signo possui, poderemos pensar na possibilidade de que o autor pode não ser o dono soberano de suas palavras, mas, ao mesmo tempo, habilita-se, por meio de suas escolhas discursivas, a tomar posse de enunciados e significá-los dentro de sua obra, para que se apresentem como seus. 
É relevante refletirmos sobre essa possibilidade de apropriação em Foucault, pois isso torna possível pensarmos no processo de autoria também regido pela premissa da subjetividade. Apesar da notória importância social na função do autor, não podemos pensá-lo como uma marionete facilmente manipulável. Contrariamente, o autor funciona socialmente dentro de suas escolhas subjetivas e é rechaçado ou aplaudido por conta das mesmas que se expressam em sua autoria.

O terceiro elemento, relacionado à atribuição, justifica aquilo que já foi mencionado em linhas anteriores sobre a autoria não ser autossuficiente na perspectiva foucaultiana. Isso se deve ao fato de que o autor não exerce sua função social baseado apenas no que produz ou na noção que faz de si mesmo. Ainda, o autor conta com as formas como a sociedade o enxerga e verifica sua relevância.

Dessa forma, ao autor são atribuídos, socialmente, certos lugares de existência que são determinados por critérios que podem ou não concordar com sua subjetividade. Esse aspecto mostra-se interessante ao posicionarmos as percepções foucaultianas sobre $\mathrm{o}$ autor em nossa sociedade contemporânea. Quando lidamos com a escrita em circunstâncias avaliativas, por exemplo, encaramos um estabelecimento institucional de autoria idealizada que se confronta com esse autor, punindo-o ou acolhendo-o, conforme seu nível de aproximação com tais pressupostos.

O quarto e último aspecto, que se refere à posição do autor, traz à tona aquilo que podemos entender como o resultado da autoria em sociedade. $\mathrm{O}$ autor ganha sua posição, seja nas seções de um livro ou em outras esferas discursivas à medida que a interação eleva seu discurso a um plano mais referencial. Em outras palavras, os demais sujeitos se referem ao autor quando encontram nele a força discursiva capaz de dar conta de suas próprias incompletudes, as quais os motivam a buscar outros dizeres na perspectiva de encontrar aprimoramentos.
Outra pontuação importante desse aspecto se concentra no status que o autor adquire quando alcança a função de referência. É possível compreendermos a posição desse autor como a materialização de seu processo de inserção social. Como exemplo, verificamos que autores como Foucault e Bakhtin são constantemente posicionados e referenciados em nossos enunciados, o que significaria, dentro da proposta foucaultiana, que seus nomes já foram validados socialmente, podendo ser retomados e desempenhar um novo tipo de função: o de auxiliar na composição da função de novos autores, dando continuidade ao ciclo.

As proposições de Foucault acerca do autor colaboram com o presente trabalho por guiarem o horizonte analítico com vistas a identificar de que maneiras o autor do Enem, idealizado como aquele que atinge nota 1000 na competência relacionada à autoria (que será analisada), adquire de maneira instantânea essa função no plano discursivo do Exame. Em outras palavras, os postulados foucaultianos são relevantes, pois nos permitem compreender como na sociedade, em grande parte ainda em fase escolar, é imposto um modo de autoria, a partir de um paradigma bem definido, com representatividade discursiva e social que força os sujeitos a repeti-lo, na busca por alcançar e pertencer a tal idealização.

A partir das notórias contribuições da perspectiva em torno da função do autor por Foucault, nos lançaremos, na seção seguinte, a analisar criticamente a cartilha de redação do Enem de 2016, publicada e divulgada pelo Inep, que autor e/ou que autoria estão no horizonte do Estado brasileiro em relação à produção de textos para o Enem. 


\section{A AUTORIA E O AUTOR NA "ERA ENEM"3}

Nesta seção, e já incomodados com algumas reflexões sobre a avaliação da autoria lançadas anteriormente, analisaremos as perspectivas do manual de redação do Enem de 2016, publicado pelo Inep, a respeito da autoria. O principal objetivo vislumbrado nesta etapa é analisar dialogicamente aquilo que o sistema de avaliação de texto do Enem enxerga como autoria, bem como suas perspectivas e expectativas sobre $\mathrm{o}$ sujeito autor.

O e-book Redação do Enem 2016: cartilha do participante é um manual digital fornecido pelo Inep gratuitamente em sua plataforma virtual constituído de duas partes. Na primeira, há explicações acerca da estrutura da redação do Enem, bem como dos critérios de avaliação dos textos. Nessa parte do manual, a tabela de competências, quadro de referência para a avaliação das redações, é explicada e acompanhada de exemplos que indicam como as pontuações são aplicadas. $\mathrm{Na}$ segunda parte, há redações que obtiveram nota 1000 no Enem em edições passadas. Esses textos são acompanhados de comentários da banca avaliadora que justificam as notas alcançadas.

Apesar da configuração de um autor e texto ideal dentro de um sistema de avaliação nacional como o Enem ser um elemento bastante instigante para nossas problematizações, nossa atenção principal será na primeira parte do documento, em que há posicionamentos e perspectivas acerca da autoria, a partir do olhar institucional do Estado que aplica e avalia as provas de redação. Especificamente, nos ateremos à competência 3 , do quadro de

\footnotetext{
3 "Era Enem" (BRAMBILA, 2017) é um termo que propõe que o Exame Nacional do Ensino Médio, diante de seu grande alcance e influência na vida dos brasileiros, não pode mais ser compreendido como apenas uma avaliação, mas sim como um contexto político e social que tem regido e delineado caminhos a esferas sociais importantes, dentre elas a escola brasileira.
}

referência do Enem que pode ser visualizado a seguir.

Quadro 1: competências do manual de redação do Enem

\begin{tabular}{|l|l|}
\hline Competência 1 & $\begin{array}{l}\text { Demonstrar domínio da } \\
\text { modalidade escrita formal } \\
\text { da língua portuguesa. }\end{array}$ \\
\hline Compreender a proposta de \\
redação e aplicar conceitos \\
das várias áreas de \\
conhecimento para \\
desenvolver o tema, dentro \\
dos limites estruturais do \\
texto dissertativo- \\
argumentativo em prosa.
\end{tabular}

Fonte: Inep (2016).

A competência 3 , que se refere à capacidade de selecionar, relacionar, organizar e interpretar informações, fatos, opiniões e argumentos em defesa de um ponto de vista, já se apresenta passível de problematizações em sua definição. Em primeira leitura, por se tratar de competência, termo que nos remete a noções próximas da cognição e do que é individual. Em segunda instância, notamos que a proposição de avaliação de competência para esse tipo de atividade humana com a linguagem configura-se, consequentemente, como uma forma de demarcar subjetividades que são mais ou menos competentes para essa realização. Apesar de já estar claro no referido guia que textos com posicionamentos que firam os 
direitos humanos serão desclassificados do exame, o que em nossa leitura é algo louvável, ainda há a pressuposição de que nem toda forma de relacionamento e/ou interpretação do tema será acolhida pela banca avaliadora.

A avaliação das formas com que o sujeito se relaciona e dialoga com uma determinada temática é, consequentemente, uma avaliação que ultrapassa as delimitações do texto e passa a julgar a subjetividade de cada um. Dentro da circunstância avaliativa de proporção nacional que é o Enem, esse tipo de avaliação erradia um modus operandi de ser, que precisará se refletir no texto, para que $o$ candidato seja considerado competente nesse quesito ao paradigma do exame.

Ainda, e pensando na autoria, principalmente sob um viés dialógico de observação, não é possível conceber que nesta competência haverá acolhimento das subjetividades e identidades diversas refletidas no texto a respeito da temática proposta. Contrariamente, e para dar conta do grande volume de redações que o Enem recebe todos os anos, o sistema de avaliação de texto fica fadado a estipular uma identidade autoral pré-definida como idealizada, o que beneficiará candidatos que melhor dominem a repetição dessa identidade.

Para dar ainda mais base a essa primeira problematização da análise, podemos citar a divulgação dos textos nota 1000 , na segunda parte do manual. Parecenos, inclusive, estratégico ao sistema de avaliação do Enem ditar suas expectativas não só textuais, mas também discursivas e autorais, e expor textos ideais dentro dessa conjuntura. Tal proposta corrobora para a implementação de uma noção fragmentada e cartesiana do processo de enunciação na superfície do texto, fazendo com que esta arena perca sua potencialidade dialógica e se configure como área de silenciamento e subserviência discursiva.

Sigamos, então, para a estrutura avaliativa da competência 3 , que se autodenomina como responsável pela avaliação da autoria. Assim como ocorre nas demais competências, a 3 é introduzida por uma sucinta explicação de seus critérios de avaliação, seguida de uma tabela em que simulações de pontuações são dadas, e de após uma rápida explicação do manual, justificando o que é preciso para atingir tal nota.

O texto da competência 3 , assim como ocorre nas outras competências, evidencia a interlocução com o sujeito candidato, deixando claro que há uma voz institucional discursiva que sabe que está sendo recepcionada por um sujeito que tem a intenção ou está prestes a fazer parte do sistema de avaliação do Enem. É possível identificar tal aspecto diante de expressões como "em seu texto", "a forma como você seleciona, relaciona, organiza..." (BRASIL, 2016, p 14), "você deve procurar atender às seguintes exigências" BRASIL, 2016, p. 14), entre outros.

Ao destacarmos essa característica do material na competência que, muito provavelmente, mais se aproxima da singularidade subjetiva do sujeito candidato, temos a clareza de que há uma intenção para além da descrição do sistema avaliativo, alcançando um panorama que dita a forma na qual o texto precisa ser produzido aos que ainda farão o exame.

Podemos, entretanto, ser facilmente confrontados com o aspecto generalista das exigências da competência 3, como é possível observar em (BRASIL, 2016, p. 21).

\footnotetext{
- apresentação clara da tese e seleção dos argumentos que a sustentam;

- encadeamento das ideias, de modo que cada parágrafo apresente informações novas, coerentes com o que foi apresentado anteriormente, sem repetições ou saltos temáticos;

- congruência entre as informações do texto e a realidade;

- precisão vocabular
}

Apesar da presença de aspectos comumente observados em avaliações de texto em geral, precisamos retomar à lembrança que no mesmo manual há as 
redações nota 1000, que aparecem como formatos prontos de textos que realizam essas exigências de uma maneira muito específica, garantindo a nota máxima.

Assim, detectamos como passível de problematização a combinação quesito + molde, existente no manual, motivados principalmente pela abrangência e influência do Enem na sociedade brasileira. Afinal, diante da obrigatoriedade de se produzir um texto, em um gênero que se repete todos os anos, e tendo ao alcance modelos institucionalmente bem avaliados, qual seria o espaço da escrita como arena tensa e dialógica na sociedade brasileira contemporânea da "era Enem"? E qual seria o espaço para uma enunciação autoral?

Por fim, chegamos ao quadro com simulações de notas que o candidato pode obter na competência 3, com breves descrições do que foi feito para que a nota tenha sido obtida.

Quadro 2: tabela de notas para a competência 3

\begin{tabular}{|c|c|}
\hline 200 pontos & $\begin{array}{l}\text { Apresenta informações, fatos e } \\
\text { opiniões relacionados ao tema } \\
\text { proposto, de forma consistente e } \\
\text { organizada, configurando } \\
\text { autoria, em defesa de um ponto } \\
\text { de vista. }\end{array}$ \\
\hline 160 pontos & $\begin{array}{l}\text { Apresenta informações, fatos e } \\
\text { opiniões relacionados ao tema, } \\
\text { de forma organizada, com } \\
\text { indícios de autoria, em defesa de } \\
\text { um ponto de vista. }\end{array}$ \\
\hline 120 pontos & $\begin{array}{l}\text { Apresenta informações, fatos e } \\
\text { opiniões relacionados ao tema, } \\
\text { limitados aos argumentos dos } \\
\text { textos motivadores e pouco } \\
\text { organizados, em defesa de um } \\
\text { ponto de vista. }\end{array}$ \\
\hline 80 pontos & $\begin{array}{l}\text { Apresenta informações, fatos e } \\
\text { opiniões relacionados ao tema, } \\
\text { mas desorganizados ou } \\
\text { contraditórios e limitados aos } \\
\text { argumentos dos textos } \\
\text { motivadores, em defesa de um } \\
\text { ponto de vista. }\end{array}$ \\
\hline 40 pontos & $\begin{array}{l}\text { Apresenta informações, fatos e } \\
\text { opiniões pouco relacionados ao } \\
\text { tema ou incoerentes e sem } \\
\text { defesa de um ponto de vista. }\end{array}$ \\
\hline
\end{tabular}

\begin{tabular}{|l|l|}
\hline \multirow{0}{*}{ ponto } & $\begin{array}{l}\text { Apresenta informações, fatos e } \\
\text { opiniões não relacionados ao } \\
\text { tema e sem defesa de um ponto } \\
\text { de vista. }\end{array}$ \\
\hline
\end{tabular}

Fonte: Inep (2016).

Interessa-nos, aqui, destacar que em momento algum do texto descritivo da competência 3 (Quadro 1) o termo "autoria" foi mencionado, tampouco houve qualquer atenção do manual em especificar o que se considera como autoria (ou a falta dela). Mesmo assim, notamos que o termo aparece na tabela da competência, sendo diretamente relacionado com a pontuação recebida.

Compete à análise proposta também evidenciar a expressão "ponto de vista", presente nas quatro últimas pontuações, sendo apenas acrescida do termo "autoria" nas duas primeiras. Apreende-se dessa organização que há na voz institucional do Estado uma delimitação clara do ponto de vista com e sem autoria, apesar de não haver quaisquer explicações ao longo do material que evidenciem como se define essa cisão.

A falta de clareza explicitada no parágrafo anterior, quando levado em conta o lugar marginalizador que a voz do Estado pode atingir em suas diretrizes acerca da produção textual, são encarados como indícios de que a autoria no Enem está afastada de sua interface dialógica, uma vez que a falta de enunciados concretos que evidenciem suas nuances demanda do candidato a repetição de propostas de escrita arbitrariamente definidas como apropriadas para essa avaliação.

Diante dessa circunstância, evidenciamos que o manual não deixa claro em que ponto de vista sobre a autoria a pontuação está baseada, o que parece problemático, visto que o mesmo documento se direciona a sujeitos que precisarão se colocar como autores de seus textos. Pode-se constatar, todavia, que a presença de autores/redações nota 1000 no mesmo manual é o que fornece indícios sobre que concepção de autoria o Estado demanda, construindo a ideia de que esse 
processo é passível de repetição, destituindo o sujeito dessa dinâmica com a linguagem.

Focalizando a discussão nas duas primeiras linhas da tabela, correspondentes à primeira e à segunda maiores notas da competência 3, em que o termo "autoria" é mencionado, encaramos novamente $\mathrm{o}$ caráter fragmentado da produção de textos para o Enem, que se reflete também em uma visão cartesiana sobre o processo da autoria. Ao mencionar que a autoria se configura diante de determinadas atitudes, há uma proposta de caráter equacional do processo autoral. Parece-nos que a autoria no Enem acontece da seguinte forma:

\section{Informações + fatos + opiniões $=$ autoria}

Essa esquematização, por nós ilustrada, à qual a tabela faz alusão, e que nos parece problemática do ponto de vista linguístico-discursivo, pois estamos nos referindo a um processo dialógico do sujeito com a linguagem e com seu outro, deixa transparecer um retrocesso na relação com a linguagem, mostrando-se grave, visto que essa perspectiva precisará ser fortemente trabalhada no final do Ensino Médio, quando os estudantes já farão o Enem.

$\mathrm{Na}$ segunda linha, não se menciona uma autoria plena, completa, finalizada em si mesma, como parece na nota mais alta. Fala-se agora de "indícios de autoria", isto é, de uma autoria aparentemente incompleta e que se difere da ideal pela falta de consistência, termo presente na primeira linha e ausente na segunda. Tal panorama é problemático, pois pressupõe uma realização subjetiva e autoral, que precisará ser tanto bem traduzida pelo candidato no tempo-espaço que tem de realização da prova de redação, quanto para o avaliador, que precisará julgar se naquele tempoespaço houve uma revelação consistente da autoria do sujeito que produziu aquele texto.

Certamente, podemos lidar tanto com a hipótese de que há um contrassenso naquilo que a competência 3 estipula que deve ser alcançado em relação à autoria, como também podemos levantar a possibilidade de que há uma percepção rasa a respeito da autoria, ignorando sua existência como processo tenso e dialogal, como nos alertam Bakhtin e Foucault, para uma simplificação equacionada que coloca a própria existência do sujeito em seu texto em xeque.

O último destaque dessa análise destina-se ao sujeito candidato, que, pela boa realização da competência 3 , se torna autor para o sistema de avaliação de texto do Enem. Não pretendemos, com isso, diminuir a potencialidade dialógica da autoria de cada um perante sua produção textual, mas sim questionar uma pressuposição tão imediatista do "tornar-se" autor para o sistema de avaliação de texto do Enem, sistema este que pode também ser compreendido como um cronotopo institucional (BRAMBILA, 2018).

Como exemplo, os autores e textos nota 1000 , expostos no manual de redação do Enem, podem ser percebidos como representações do que é ser autor para o Enem. Por terem atingido a nota máxima em todas as competências, inclusive a que trata da autoria, os autores desses textos são enunciados pelo sistema como detentores de uma autoria plena, integral, sistematizada como a união de informações, fatos e opiniões.

Tal dado colabora com a recuperação da própria noção de autor, em Foucault, principalmente no que toca sua função. Os autores de redações nota 1000, ao terem sua autoria consolidada e certificada como completa pelo sistema de avaliação, são deslocados de seu contexto de vida - visto que alguns desses autores podem estar apenas completando sua formação básica na escola regular -, para tornarem-se balizas linguístico-discursivas do que é recomendado e do que precisa ser retomado para que se entre nesse sistema.

Desse modo, a construção da redação com autoria nota 1000 pode ser considerada um modelo de representação, que constitui um sujeito-autor bem definido, repetível, para fora de suas relações dialógicas com a linguagem. A partir de tal 
circunstância, é facilmente possível que haja certa deturpação da constituição autoral, criando o imaginário de que ela se basta a tirar a nota máxima em uma prova de redação.

Com isso, é possível constatarmos que os autores nota 1000, ao serem colocados em um manual de redação do Estado, ganham um estatuto de autores similar à concepção de autoria foucaultiana. Entretanto, esse estatuto se dá de maneira muito mais instantânea, o que beiraria a uma autoria líquida, em uma sociedade que assim também é (BAUMAN, [1999] 2001), o que nos leva à reflexão de que a tensão discursiva do sujeito com seu texto tem perdido força para que necessidades aparentemente emergenciais, como tirar uma boa nota no Enem, se concretizem.

\section{CONCLUSÕES}

Apropriando-nos das reflexões já tecidas no decorrer do texto, pontuamos algumas observações que tocam não apenas o lugar da autoria na produção de textos para o Enem, mas também na sociedade brasileira contemporânea.

A autoria para a redação do Enem, diante do estudo dialógico da tabela de competências, nos é apresentada como uma combinação de habilidades específicas que, se repetidas, garantem ao candidato $o$ sucesso no ingresso em uma universidade. Em outras palavras, haverá uma consciência dualista: a de "autoria certa" e a de "autoria errada", visto que tal processo é explicado de maneira cartesiana como resultado configurado da soma de informações, fatos e opiniões.

O que nos parece preocupante na perspectiva percebida é um fazer autoral que não necessariamente se atrela à subjetividade do candidato que se coloca a escrever. Há uma subjetividade subjacente, individual, próxima da ideia cognoscente do ser. Pela análise, não se torna possível encarar uma perspectiva de sujeito dialógico, social e histórico e dialético. Por isso, a base da proposta de avaliação da prova de redação do Enem é psicologicista, no sentido proposto por Bakhtin/Volochínov (2011; 2012), indo na direção da ideologia meritocrática e, consequentemente, neoliberal. Os indivíduos que, praticamente sozinhos, conseguirem se apropriar do modelo de autor proposto, merecem fazer parte do sistema, o que não dá qualquer garantia de que esse seja um sistema para todos. Ademais, constata-se aqui que há um afastamento do processo de escrita como interação humana, tensa e dialógica, para dar lugar a uma instrumentalização do ato de escrever, aproximando-o de uma combinação repetida de registros.

Tal reflexão acerca do (não) lugar da autoria na produção de textos para o Enem mostra-se também preocupante pelo caráter decisivo que o exame tem na vida de jovens de todo o território nacional. Atrelada a um caráter redentorista, em uma sociedade que se segrega socialmente também pela presença/ausência de diploma universitário, a prova de redação do Enem carrega um discurso institucional de que a subserviência textual, discursiva e ideológica a uma produção de textos específica garantirá a entrada em uma universidade pública e, consequentemente, uma mudança de vida. Diante de tal oferta, parece-nos claro que questões da ordem da subjetividade serão sublimadas para que a urgência da aprovação seja alcançada.

Trazendo a questão para um nível macro de discussão podemos, também, enxergar que essa nova perspectiva em torno da autoria também afeta a relação que o sujeito tem com seu fazer textual e autoral em outros âmbitos de escrita. Isso nos é claramente visualizado com a realidade de escolas públicas e particulares que, no Ensino Médio, se veem obrigadas a focalizar sua prática com a área da linguagem pensando na redação do Enem, sempre na tentativa de conseguir em seu curto tempo-espaço, moldar autores ao estilo do exame que se encaixem nesse sistema. 
Ainda, e como consequência da realidade trazida no parágrafo anterior, o ensino-aprendizagem de textos e a interação com gêneros discursivos na esfera escolar passam a ser cada vez mais afunilados, especificando tarefas e não necessariamente propiciando interações dialógicas $\mathrm{e}$ significativas na e pela linguagem.

Portanto, este trabalho buscou, ao longo de seu desenvolvimento, adicionar

\section{REFERÊNCIAS}

BAKHTIN, M. Problemas da Poética de Dostoiévski. Tradução de Paulo Bezerra. Rio de Janeiro: Forense Universitária, 2005.

BAKHTIN, M. O autor e a personagem. In: BAKHTIN, M. Estética da criação verbal. São Paulo: Martins Fontes, $6^{\mathrm{a}}$ ed., 2011, p. 3-20.

BAKHTIN, M.; VOLOCHÍNOV, V. O Freudismo: um esboço crítico. 2. ed., São Paulo: Perspectiva, 2012.

BAKHTIN, M.; VOLOCHÍNOV, V. Marxismo e filosofia da linguagem. São Paulo: Hucitec, 2011.

BAUMAN, Z. Modernidade Líquida. $1^{\text {a }}$ ed. Rio de Janeiro: Zahar Editora, [1999] 2001.

BRAMBILA, G. O texto em avaliação: do gênero discursivo ao cronotopo. Percursos Linguísticos (Ufes), v. 8, n. 20, 2018, p. 117-131.

BRAMBILA, G. A produção de textos na "era Enem": subjetividade e autoria no contexto político-pedagógico brasileiro contemporâneo. Dissertação de Mestrado (PPGEL - Ufes). Vitória, ES. 2017. Disponível em <http://repositorio.ufes.br/bitstream/10/1034 8/1/tese_11530_DISSERTA\%c3\%87\%c3\% 830\%20COMPLETA\%20GUILHERME\% 20BRAMBILA\%20MANSO.pdf $>$. Acesso em: 03 out. 2019. mais um diálogo a uma área de investigação tão densa como os estudos da avaliação textual, em especial a da redação do Enem. Percebe-se, com isso, que inúmeras questões e problematizações de ordem textual, discursiva e sociológica podem emergir desse campo, cabendo a nós, enquanto sociedade, debatermos tais temas em todas as esferas, inclusiva a dos estudos da linguagem.

BRASIL. Redação do Enem 2016: cartilha do participante. Ministério da Educação, $1^{\text {a }}$ ed., 2016. Disponível em: <http://download.inep.gov.br/educacao_basi ca/enem/guia_participante/2016/manual_de _redacao_do_enem_2016.pdf>. Acesso em: 04 maio 2017.

CLARK, K.; HOLQUIST, M. Mikhail Bakhtin. São Paulo: Perspectiva, 2004.

DORIGATTI, B. Ascenção e declínio do autor. I Seminário Brasileiro sobre Livro e História Editorial (UFF). Casa Rui Barbosa, Rio de Janeiro, 2004, p. 1-9.

FARACO, C. A. Autor e autoria. In: BRAIT, B. (org.). Bakhtin: conceitoschave. São Paulo: Contexto, 2005, p. 37-60.

FOUCAULT, M. O que é um autor? (1969) In: Ditos e Escritos - Estética: literatura e pintura; música e cinema. Rio de Janeiro: Forense Universitária, 2006, p. 264-298.

GINZBURG, C. Mitos, Emblemas, Sinais: morfologia e história. São Paulo: Companhia das Letras, 1986.

POSSENTI, S. Enunciação, autoria e estilo. Revista FAEEBA, Salvador, v. 10, n.15, 2001, p. 15-21.

VIDON, L. N. A prática escolar de ensino de gêneros do discurso argumentativo: pedagogia da dessubjetivação. Estudos 
Linguísticos, São Paulo, 42 (2): p. 743-755, Problemas fundamentais do método 2013. sociológico na ciência da linguagem.

VOLÓCHINOV. V. (Círculo de Bakhtin). Américo. Editora 34, 2017. Marxismo e Filosofia da Linguagem. 